\title{
Density-Functional Study on the Origin of Ferromagnetism in Copper Doped Aluminium Nitride
}

\author{
H.M. Zhao \\ Teaching and Research Institute of Foreign Languages \\ Bohai university \\ Jinzhou, China
}

\begin{abstract}
Recently, room-temperature ferromagnetism was reported in Cu-doped AIN film. However, a systematic study on the magnetic mediation of intrinsic vacancy is still absent and the origin of ferromagnetism of $\mathrm{Cu}$-doped AIN remains unclear. We investigate the magnetic properties of $\mathrm{Cu}$-doped AIN by firstprinciples calculations. Our results reveal that the ferromagnetism is very weak for $\mathrm{Cu}$ substitution only. However, both the anion and cation vacancies can mediate the ferromagnetism effectively. Under the $\mathrm{N}$-poor conditions, the defect complex with $\mathbf{N}$ vacancy has much lower formation energy and the origin of ferromagnetism can be attributed to the $\mathrm{N}$ vacancy mediated $p-d$ hybridization.
\end{abstract}

Keywords-ferromagnetism; cu-doped AlN; intrinsic vacancies; first-principles study

\section{INTRODUCTION}

Diluted magnetic semiconductors (DMSs) are new materials that explore both charge and spin degrees of freedom and therefore are promising for spintronics.[1,2] For application purposes, DMSs must have robust ferromagnetism, which remains stable at room-temperature (RT), and meanwhile possesses the semiconductor properties. Generally, ferromagnetism can be obtained by doping magnetic elements into wide band-gap semiconductors. For instance, RT ferromagnetism has been reported in $\mathrm{Fe}, \mathrm{Co}$ and $\mathrm{Ni}$ doped semiconductors of oxide and nitride.[3,4,5,6] However, the clustering of magnetic impurities and the formation of secondary phases often make the ferromagnetism extrinsic and prevent their further applications. Moreover, the doped magnetic elements do not lead to ferromagnetism definitely and experiments often found that ferromagnetism had close relation to the presence of intrinsic vacancies.[7,8,9] To exclude the contamination of magnetic elements, researchers doped light elements into semiconductors and consequently found RT ferromagnetism in the doped systems, which was called $d^{0}$ ferromagnetism.[10] Experimentally, RT ferromagnetism was reported in C-doped $\mathrm{ZnO}$ and $\mathrm{SnO}_{2}$.[11,12] Theoretical studies reveal that holes in valence band play an important role in $d^{0}$ ferromagnetism. By doping impurities with weaker electronegativity or lower valence into semiconductors of oxide or nitride, holes are introduced into the valence band of semiconductors, which leads to band magnetization.[13] As a nonmagnetic element, copper is often doped to many semiconductors to fabricate DMSs. Experimentally, RT ferromagnetism was reported in $\mathrm{Cu}$ doped
$\mathrm{ZnO}, \mathrm{SnO}_{2}$, and $\mathrm{TiO}_{2} \cdot[14,15,16]$ The origin of ferromagnetism is often attributed to the mediation of oxygen vacancy. Nevertheless, studies also reveal that it is cation vacancies rather than anion vacancies that mediate the ferromagnetism effectively in some transition-metal (TM) doped semiconductors.[17,18] Surprisingly, the magnetic mediation of cation vacancies is often neglected in many studies. Recently, Ran et al. found RT ferromagnetism in $\mathrm{Cu}$-doped AlN.[19] It provides a new way to obtain the DMSs free of magnetic elements. Although several theoretical studies have been done on the magnetic properties of Cu-doped AlN,[20,21] a systematic study on the magnetic mediation of intrinsic vacancies is still absent. Therefore, the origin of ferromagnetism is still unclear and needs further investigations.

In this article, we investigate the magnetic properties of $\mathrm{Cu}$-doped $\mathrm{AlN}$ by first-principles calculation. Our results reveal that the magnetic coupling is weak when $\mathrm{Cu}$ substitution occurs only, and therefore, the mediation of intrinsic vacancies must be considered. Ferromagnetism is enhanced for the doped system when $\mathrm{N}$ or Al vacancy is present. Under $\mathrm{N}$-poor condition, the formation energy of $\mathrm{N}$ vacancy is much lower than that of $\mathrm{Al}$ vacancy, and therefore, $\mathrm{N}$ vacancy is much easier to form than $\mathrm{Al}$ vacancy. The origin of RT ferromagnetism can be attributed to the Nvacancy mediated $p-d$ hybridization.

\section{CAlculation Details}

A supercell of size $2 \times 2 \times 3$ is built from the unit cell with space group $P 63 \mathrm{mc}$. We perform density-functional calculations based on the full-potential linear augmented plane waves plus local orbital methods (LAPW+lo), as implemented in WIEN2K computing package, on the magnetic properties of $\mathrm{Cu}$-doped AlN. The muffin-tin spheres are set to be 1.8, 2.1, and 1.6 Bohr for $\mathrm{Al}, \mathrm{Cu}$ and $\mathrm{N}$ atoms respectively. The generalized-gradient-approximation of Perdew-BurkeErnzerhof form is used for the exchange-correlation potential. The waves inside the spheres are expanded by harmonic spherical functions up to $l=10$. In the interstitial regions, the waves are expanded by plane waves, which are cut off by setting $R \cdot K_{\max }=8.0$. An energy cut-off of $-6.0 \mathrm{Ry}$ is used to separate the core states from those valence states. Before the calculations, the doped structures are fully relaxed from geometry and internal atom positions until the force between atoms is less than $1.0 \mathrm{mRy} / \mathrm{Bohr}$. 


\section{RESULTS AND DISCUSSIONS}

\section{A. Roles of $\mathrm{Cu}$ Substitution}

By introducing one $\mathrm{Cu}$ into the supercell, we investigate the magnetic properties of $\mathrm{Cu}$-doped $\mathrm{AlN}$ with impurity concentration $4.2 \%$. Both the spin-polarized and nonmagnetic calculations are performed and we find that the doped system prefers the spin-polarized state, which is $0.18 \mathrm{eV}$ in energy lower than the nonmagnetic state. Totally, 2.00 $\mu_{B}$ is induced in the supercell by introducing one $\mathrm{Cu}$, which is close to the moment of $2.05 \mu_{B}$ induced in Cu-doped $\mathrm{SnO}_{2}$.[17] This is consistent with other results of calculations.[20,21] The local moment of $\mathrm{Cu}$ is $0.68 \mu_{B}$ and the $\mathrm{N}$ atoms nearest to $\mathrm{Cu}$ have a moment of $0.20 \mu_{B}$ on average. The $\mathrm{N}$ atoms next-nearest to $\mathrm{Cu}$ have a moment of $0.014{ }^{\mu_{B}}$. Negligible moments are also induced for $\mathrm{Al}$ atoms, which couple to the nearest $\mathrm{N}$ atoms ferromagnetically. To investigate the magnetic properties, we calculate the total and projected density of states (DOSs) for the Cu-doped AlN.

To investigate the magnetic coupling between impurities, we introduce two impurities into $\mathrm{Al}$ sites, which correspond to the concentration of $8.33 \%$. Both ferromagnetic and antiferromagnetic states are calculated and we define the magnetization energy $\Delta E_{M}=E_{A F}-E_{F M}$. A positive value means the ferromagnetic state is stable and vice versa. The magnetization energy together with the total moments is listed in the table 1.

TABLE I. MAGNETIZATION ENERGY TOGETHER WITH TOTAL MOMENTS INDUCED IN THE SUPERCELLS FOR THE DOPED STRUCTURES. D IS THE DISTANCE BETWEEN THE IMPURITIES. MCELL IS THE TOTAL MOMENTS FOR THE FERROMAGNETIC STATE.

\begin{tabular}{|c|c|c|c|}
\hline Configurations & $d(\AA)$ & $\Delta E_{M}$ & $\begin{array}{c}M_{\text {cell }}( \\
\left.\mu_{B}\right)\end{array}$ \\
\hline $\mathrm{Cu}_{\mathrm{Al}}(\mathrm{C} 1, \mathrm{C} 2)$ & 3.10 & -15.8 & 1.51 \\
\hline $\mathrm{Cu}_{\mathrm{Al}}(\mathrm{C} 1, \mathrm{C} 3)$ & 4.41 & 5.0 & 4.00 \\
\hline $\mathrm{Cu}_{\mathrm{Al}}(\mathrm{C} 1, \mathrm{C} 4)$ & 5.05 & -2.0 & 4.00 \\
\hline $\mathrm{Cu}_{\mathrm{Al}}(\mathrm{C} 1, \mathrm{C} 5)$ & 7.78 & 11.7 & 4.00 \\
\hline $\mathrm{Cu}_{\mathrm{Al}}(\mathrm{C} 1, \mathrm{C} 6)$ & 8.39 & 13.4 & 4.00 \\
\hline
\end{tabular}

It is noticed that the magnetization energy varies from negative to positive values and the maximum value is less than the thermal fluctuation of room-temperature, which means the room-temperature ferromagnetism is absent for the system with $\mathrm{Cu}$ substitution only. When $\mathrm{Cu}$ impurities get closer, the total moments decrease to $1.51 \mu_{B}$ for the supercell. Moreover, our calculations reveal that the structure $(\mathrm{C} 1, \mathrm{C} 2)$ is $0.5 \mathrm{eV}$ lower in energy than other structures, which means that $\mathrm{Cu}$ impurities are inclined to form clusters in AlN.

\section{B. Mediation of Intrinsic Vacancies}

It is important to investigate the magnetic mediation of intrinsic vacancies since they play an important role in TMdoped semiconductors. It was reported that anion vacancies mediated ferromagnetism in many TM-doped semiconductors. By introducing one $\mathrm{N}$ vacancy and two $\mathrm{Cu}$ impurities, we investigate the magnetic mediation of $V_{\mathrm{N}}$ in $\mathrm{Cu}$-doped AlN. The magnetization energy as well as the total moments induced for the ferromagnetic states is listed in table 2. It is noticed that strong ferromagnetism emerges when $\mathrm{N}$ vacancy is introduced into $\mathrm{Cu}$-doped $\mathrm{AlN}$. The ferromagnetism is strengthened compared to that of the systems without $V_{\mathrm{N}}$.

Total moments of $3.00 \mu_{B}$ are induced for the ferromagnetic state of most structures. $\mathrm{Cu}$ impurity has a local moment of $0.30 \mu_{B}$ and the nearest $\mathrm{N}$ atoms have a moment of 0.16 $\mu_{B}$ on average. The total and projected density of states for the configuration $\mathrm{Cu}_{\mathrm{Al}}(\mathrm{C} 1 . \mathrm{C} 5)+V_{\mathrm{N}}(\mathrm{A} 2)$ in ferromagnetic state are calculated.

Compared to the doped system without vacancy, the splitting of valence band is enhanced. The majority states are totally pushed down to the Fermi level and the minority states are pushed above the Fermi level. For both $\mathrm{Cu}$ and $\mathrm{N}$ atoms, the peaks at the Fermi level become sharper, indicating the stronger $p$ - $d$ hybridization. Local states are also introduced into the band gap by $\mathrm{Al}$ atoms and the band gap becomes narrower compared to that of the system without $V_{\mathrm{N}}$. Due to the donor character of $V_{\mathrm{N}}$, the holes introduced by $\mathrm{Cu}$ impurities are partially removed by $V_{\mathrm{N}}$ and this consequently reduces the total moments in the supercell. However, $V_{N}$ only remove one hole instead of three holes in the valence band, which indicates the local character of vacancy charge.

We also investigate the magnetic mediation of cation vacancy by removing one $\mathrm{Al}$ from the $\mathrm{Cu}$-doped supercell. It is noticed that large magnetization energy emerges and the systems have large moments.

TABLE II. MAGNETIZATION ENERGY AND TOTAL MOMENTS INDUCED IN THE SUPERCELLS FOR THE DOPED STRUCTURES WITH TWO CU IMPURITIES AND ONE INTRINSIC VACANCY.

\begin{tabular}{|l|l|l|}
\hline \multicolumn{1}{|c|}{ Configurations } & $\Delta E_{M}(\mathbf{m e V})$ & $M_{\text {cell }}\left(\begin{array}{l}\mu_{B} \\
\end{array}\right.$ \\
\hline $\mathrm{Cu}_{\mathrm{Al}}(\mathrm{C} 1, \mathrm{C} 2)+V_{N}(\mathrm{~A} 1)$ & -0.1 & 1.00 \\
\hline $\mathrm{Cu}_{\mathrm{Al}}(\mathrm{C} 1, \mathrm{C} 3)+V_{N}(\mathrm{~A} 1)$ & 14.1 & 3.00 \\
\hline $\mathrm{Cu}_{\mathrm{Al}}(\mathrm{C} 1, \mathrm{C} 4)+V_{N}(\mathrm{~A} 1)$ & 2.6 & 2.70 \\
\hline $\mathrm{Cu}_{\mathrm{Al}}(\mathrm{C} 1, \mathrm{C} 4)+V_{N}(\mathrm{~A} 3)$ & 58.1 & 3.00 \\
\hline $\mathrm{Cu}_{\mathrm{Al}}(\mathrm{C} 1, \mathrm{C} 5)+V_{N}(\mathrm{~A} 1)$ & 7.7 & 3.00 \\
\hline $\mathrm{Cu}_{\mathrm{Al}}(\mathrm{C} 1, \mathrm{C} 5)+V_{N}(\mathrm{~A} 2)$ & 25.7 & 3.00 \\
\hline $\mathrm{Cu}_{\mathrm{Al}}(\mathrm{C} 1, \mathrm{C} 6)+V_{N}(\mathrm{~A} 1)$ & 19.4 & 3.00 \\
\hline $\mathrm{Cu}_{\mathrm{Al}}(\mathrm{C} 1, \mathrm{C} 6)+V_{N}(\mathrm{~A} 2)$ & 29.6 & 3.00 \\
\hline $\mathrm{Cu}_{\mathrm{Al}}(\mathrm{C} 1, \mathrm{C} 5)+V_{\mathrm{Al}}(\mathrm{C} 2)$ & 155.7 & 3.20 \\
\hline $\mathrm{Cu}_{\mathrm{Al}}(\mathrm{C} 1, \mathrm{C} 5)+V_{\mathrm{Al}}(\mathrm{C} 3)$ & 348.0 & 6.90 \\
\hline $\mathrm{Cu}_{\mathrm{Al}}(\mathrm{C} 1, \mathrm{C} 6)+V_{\mathrm{Al}}(\mathrm{C} 2)$ & 135.4 & 5.00 \\
\hline $\mathrm{Cu}_{\mathrm{Al}}(\mathrm{C} 1, \mathrm{C} 4)+V_{\mathrm{Al}}(\mathrm{C} 2)$ & -40.7 & 4.40 \\
\hline $\mathrm{Cu}_{\mathrm{Al}}(\mathrm{C} 1, \mathrm{C} 3)+V_{\mathrm{Al}}(\mathrm{C} 2)$ & 16.7 & 3.00 \\
\hline
\end{tabular}

To further investigate the magnetic properties, we calculate the density of states for the doped system with $V_{\mathrm{Al}}$. For the configuration $\mathrm{Cu}_{\mathrm{Al}}(\mathrm{C} 1, \mathrm{C} 5)+V_{\mathrm{Al}}(\mathrm{C} 2)$, more holes are introduced into the valence band and the Fermi level crosses both the majority and the minority states. Therefore, a metallic property can be expected in the doped system. The holes mainly locate on the sites of $\mathrm{Cu}$ and its nearest $\mathrm{N}$ atoms. At the 
Fermi level, sharp peaks emerge for both $\mathrm{Cu}$ and $\mathrm{N}$ atoms, indicating the strong $\mathrm{p}-\mathrm{d}$ hybridization between them. Negligible holes are also induced for $\mathrm{Al}$ atoms, which couple to their nearest $\mathrm{N}$ atoms ferromagnetically. It is noticed that both $V_{\mathrm{N}}$ and $V_{\mathrm{Al}}$ can mediate the magnetic coupling between impurities effectively and strengthen the ferromagnetism. However, compared to $V_{\mathrm{N}}$ mediation, $V_{\mathrm{Al}}$-mediated system possesses a metallic property and often has larger magnetization energy.

\section{Formation Energy of Defect Complexes}

It is important to investigate the formation energy of defect complex in $\mathrm{Cu}$-doped AIN since they play an important role in the RT ferromagnetism. The vacancies are formed only when their formation energy is much low. The formation energy of the defect complex can be written as [22,23,24,25]

$$
E_{f}=E(C u, V)-E(0,0)+\mu_{A l}+\mu_{V}-\mu_{C u}
$$

where $E(\mathrm{Cu}, V)$ is the total energy of the doped system with one defect complex, and $E(0,0)$ is the total energy of undoped system. $\mu_{A l \text { and }} \mu_{C u}$ are the chemical potentials of $\mathrm{Al}$ and $\mathrm{Cu}$ in the corresponding matter states. $\mu_{V}$ is the chemical potential of the atom removed from the system. We calculate the formation energy for both $\mathrm{Cu}_{\mathrm{Al}}+V_{\mathrm{N}}$ and $\mathrm{Cu}_{\mathrm{Al}}+V_{\mathrm{Al}}$ defect complexes under the nitrogen-poor and nitrogen-rich conditions. For the nitrogen-poor condition, the chemical potentials of $\mathrm{Al}$ and $\mathrm{Cu}$ take those of bulk metals respectively. For the nitrogen-rich condition, the chemical potential of $\mathrm{N}$ takes that of nitrogen gas. The formation energy as well as the total moments in the supercell is listed in table 3. For the substitution of $\mathrm{Cu}$, the formation energy is very high under the $\mathrm{N}$-poor condition while it is much low under the N-rich condition. This means that $\mathrm{Cu}$ can substitute $\mathrm{Al}$ heavily under $\mathrm{N}$-rich condition. In experiments, the samples were prepared under $\mathrm{N}$-poor condition and therefore, the substitution of $\mathrm{Cu}$ is very rare. Hence the average moment induced by $\mathrm{Cu}$ substitution is significantly less than the calculating value 2.0

$\mu_{B} / \mathrm{Cu}$, which is consistent with the experimental result.[19] It is noticed that $V_{\mathrm{N}}$ tends to occupy the sites nearest to $\mathrm{Cu}$ and the defect complex has much lower formation energy under $\mathrm{N}$ poor condition. For the defect complex with $\mathrm{Al}$ vacancy, the formation energy is much low under N-rich condition while it is very high under $\mathrm{N}$-poor condition. Also, $\mathrm{Al}$ vacancy is more inclined to form on the site nearest to $\mathrm{Cu}$. Therefore, we deduce that the ferromagnetism reported in experiments is mainly mediated by $V_{\mathrm{N}}$ since the samples are prepared under $\mathrm{N}$-poor condition.[19] We also notice that Al vacancy can also mediate the ferromagnetism effectively. When the samples are prepared under N-rich condition, roomtemperature ferromagnetism will also emerge.
TABLE III. THE FORMATION ENERGY AS WELL AS TOTAL MOMENTS FOR THE SYSTEMS WITH DIFFERENT VACANCIES. EF1 IS THE FORMATION ENERGY FOR THE N-POOR CONDITION. EF2 IS THE FORMATION ENERGY FOR THE N-RICH CONDITION.

\begin{tabular}{|l|l|l|l|}
\hline Configurations & $E_{f 1_{(\mathbf{e V})}}$ & $E_{f{ }^{2}(\mathbf{e V})}$ & $M_{\text {cell }}$ \\
& & & $\left.\mu_{B}\right)$ \\
\hline $\mathrm{Cu}_{\mathrm{Al}}(\mathrm{C} 1)$ & 5.6 & 0.2 & 2.00 \\
\hline $\mathrm{Cu}_{\mathrm{Al}}(\mathrm{C} 1)+V_{N}(\mathrm{~A} 1)$ & 5.0 & 5.8 & 1.00 \\
\hline $\mathrm{Cu}_{\mathrm{Al}}(\mathrm{C} 1)+V_{N}(\mathrm{~A} 3)$ & 6.4 & 7.2 & 1.00 \\
\hline $\mathrm{Cu}_{\mathrm{Al}}(\mathrm{C} 1)+V_{\mathrm{Al}}(\mathrm{C} 2)$ & 13.6 & 2.0 & 3.00 \\
\hline $\mathrm{Cu}_{\mathrm{Al}}(\mathrm{C} 1)+V_{\mathrm{Al}}(\mathrm{C} 4)$ & 14.5 & 2.9 & 4.80 \\
\hline
\end{tabular}

\section{CONCLUSIONS}

We have investigated the magnetic properties of $\mathrm{Cu}$-doped $\mathrm{AlN}$ by first-principles calculation. Our results reveal that $\mathrm{Cu}$ can substitute $\mathrm{Al}$ heavily under the N-rich condition. However, the magnetization energy is much small when $\mathrm{Cu}$ substitution occurs only and therefore the magnetic mediation of intrinsic vacancies must be considered. Both $\mathrm{N}$ and $\mathrm{Al}$ vacancies can mediate the magnetic coupling effectively. The defect complex with $\mathrm{N}$ vacancy has much lower formation energy under N-poor condition while the defect complex with $\mathrm{Al}$ vacancy has much lower formation energy under N-rich condition. For the experimental preparation, $\mathrm{Cu}$-doped $\mathrm{AlN}$ is fabricated under $\mathrm{N}$-poor condition and $\mathrm{N}$ vacancies predominate. Therefore, the RT ferromagnetism can be attributed to $V_{\mathrm{N}}$-mediated $p$ - $d$ hybridization.

\section{REFERENCES}

[1] Sato K, Bergqvist L, Kudrnovsky J, Dederichs P. H., Eriksson O, Turek I, Sanyal B, Bouzerar G, Katayama-Yoshida H, Dinh V A, Fukushima T, Kizaki H and Zeller R., Rev. Mod. Phys. 82:1633, 2010. .

[2] Awschalom D.D and Flatte M E, Nat. Phys. 3:153, 2007

[3] Hong N H, Sakai J, Prellier W, Hassini A, Ruyter A and Gervais F, Phys. Rev. B 70:195204, 2004.

[4] Hong N H, Sakai J, Huong N T and Brize V 2005 Appl. Phys. Lett. 87: 102505, 2005.

[5] Fitzgerald C.B, Venkatesan M, Dorneles L.S, Gunning R, Stamenov P, Coey J M D, Stampe P A, Kennedy R.J, Moreira E.C and Sias U.S, Phys. Rev. B 74: 115307, 2006

[6] Talut G, Reuther H, Zhou S, Potzger K, Eichhorn F and Stromberg F, J. Appl. Phys. 102: 083909, 2007.

[7] Kimura H, Fukumura T, Kawasaki M, Inaba K, Hasegawa T and Koinuma H, Apl. Phys. Lett. 80: 94, 2002.

[8] Zhang K C, Li Y F, Liu Y and Chi F, J. Appl. Phys. 114: 133707, 2013.

[9] Zhang C and Yan S, J. Appl. Phys. 106: 063709, 2009.

[10] Coey J M D, Solid State Sci. 7: 660, 2005.

[11] Pan H, Yi J.B, Shen L, Wu R.Q, Yang J.H, Lin J.Y, Feng Y.P, Ding J, Van L.H and Yin J.H, Phys. Rev. Lett. 99: 127201, 2007.

[12] Hong N.H, Song J.H, Raghavender A.T, Asaeda T and Kurisu M, Appl. Phys. Lett. 99: 052505, 2011

[13] Peng H, Xiang H.J, Wei S H, Li S.S, Xia J.B and Li J, Phys. Rev. Lett. 102: 017201, 2009.

[14] Dan X, Yao K.L, Gao G.Y and Ma G Q, Chin. Phys. B 22: 047507 , 2013.

[15] Li Y, Deng R, Tian Y, Yao B and Wu T, Appl. Phys. Lett. 100: 172402, 2012.

[16] Herng T.S, Qi D.C, Berlijn T, Yi J.B, Yang K.S, Dai Y, Feng Y.P, Santoso I, Sanchez-Hanke C, Gao X.Y, Wee A.T.S, Ku W, Ding J and Rusydi A, Phys. Rev. Lett. 105: 207201, 2010. 
[17] Duhalde S, Vignolo M.F, Golmar F, Chiliotte C, Torres C.E.R, Errico L.A, Cabrera A.F, Renteria M, Sanchez F.H and Weissmann M, Phys. Rev. B 72: 161313, 2005.

[18] Ran C.J, Yang H.L, Wang Y.K, Hassan F.M, Zhou L.G, Xu X.G and Jiang Y, Chin. Phys. B 22: 067503, 2013.

[19] Sun Y.B, Zhang X.Q,Li G.K and Cheng Z.H, Chin. Phys. B 21: 047503, 2012.

[20] Zhang K.C, Liu Y, Li Y.F and Zhu Y, J. Appl. Phys. 113: 053713, 2013.

[21] Yan W, Sun Z, Liu Q, Li Z, Pan Z, Wang J and Wei S, Appl. Phys. Lett. 91: 062113, 2007.

[22] Ran F.Y, Subramanian M, Tanemura M, Hayashi Y and Hihara T, Appl. Phys. Lett. 95: 112111, 2009.

[23] Zhang K C, Li Y F, Liu Y and Zhu Y, J. Appl. Phys. 112: 043705, 2012.

[24] Shi L.J, Zhu L.F, Zhao Y.H and Liu B.G, Phys. Rev. B 78: 195206, 2008.

[25] Zhang S.B and Northrup J.E, Phys. Rev. Lett. 67: 2339, 1991. 